\title{
Mathematical modeling of stationary thermoelastic state in a half plane containing an inclusion and a crack due to local heating by a heat flux
}

\author{
Zelenyak V. M. \\ Lviv Polytechnic National University, \\ 12 S. Bandera Str., 79013, Lviv, Ukraine
}

(Received 12 December 2019; Revised 20 January 2020; Accepted 25 January 2020)

\begin{abstract}
The two-dimensional stationary problems of heat conduction and thermoelasticity for a semi-infinite elastic body containing an inclusion and a crack are considered. For this purpose, mathematical models of these two-dimensional problems in the form of a system of singular integral equations (SIEs) of the first and the second kinds are constructed. The numerical solution of the system of integral equations in the case of a half plane containing an inclusion and thermally insulated crack due to local heating by a heat flux is obtained using the method of mechanical quadratures. We present graphical dependencies of stress intensity factors (SIFs), which characterize the distribution of intensity of stresses on the tops of a crack, on the elastic and thermoelastic characteristics of an inclusion and a matrix, as well as on a relative position of a crack and an inclusion. The obtained results are subsequently used to determine the critical values of a heat flux at which a crack starts to grow. This model is the development of known models of two-dimensional stationary problems of heat conduction and thermoelasticity for piecewise-homogeneous bodies with cracks.
\end{abstract}

Keywords: stress intensity factor, singular integral equation, inclusion, heat conduction, thermoelasticity, crack, heat flux.

2010 MSC: $74 \mathrm{~K} 25$

DOI: $10.23939 / \mathrm{mmc} 2020.01 .088$

\section{Introduction}

The two-dimensional problems of thermoelasticity for semi-infinite bodies with cracks have already been investigated in the literature. In particular, the thermoelastic state of a half plane containing an internal rectilinear crack at different temperature and force conditions imposed on the crack tips and on the edge of the half plane was analyzed in [1-3]. The method of SIE was used for the analysis of the plane thermoelastic state in a half space containing an internal arbitrary oriented rectilinear crack [4], a periodic system of cracks of this sort [5], internal curvilinear crack [6], edge crack [7] or an inclusion and a crack $[8,9]$ due to local heating over a part of its free surface by a heat flux.

The SIE of heat conduction and thermoelasticity with special Cauchy-type kernels for a plane with thermally insulated cracks or heat-conducting cuts located in a circular foreign inclusion [10], as well as for bodies with thermal cylindrical inclusions and crack [11] are deduced by the method of functions of a complex variable. The solutions of the thermoelasticity problem for a plane with a crack on the basis of the finite element method [12] and the Fourier integral transform method [13] were presented.

However, the problems of thermoelasticity remain poorly investigated for nonhomogeneous semiinfinite bodies with cracks (cuts) and in the available literature, there can be found no solutions for multi-component bodies with cracks and, in particular, for the two-component bodies with cracks.

The aim of this article is: (i) to construct a two-dimensional mathematical model of the stationary problems of heat conduction and thermoelasticity for an elastic half plane containing an inclusion and a crack in the form of a system of singular integral equations (SIE); (ii) to determine the numerical solutions of SIE (employing the method of mechanical quadratures) in the particular case of a circular 
inclusion and thermally insulated crack when a half plane is heated at a part of its free edge by a constant-intensity heat flux. This makes it possible to determine stress intensity factors (SIF) at the tops of the crack.

\section{Statement of the problem}

In this paper, we consider an elastic half plane containing an elastic circular inclusion with contour $L_{1}$ and internal rectilinear thermally insulated crack $L_{2}$ (see Fig. 1). We assume that contours $L_{n}, n=1,2$ do not have common points. Each contour is connected with a local coordinate systems $x_{k} O_{k} y_{k}$, and the points $O_{k}$ are determined in the coordinate system $x O y$ by complex coordinates $z_{n}^{0}=x_{n}^{0}+i y_{n}^{0}$, the relationship between these coordinate systems is specified by the relations $z=z_{n}+z_{n}^{0}, z=x+i y$, $z_{n}=x_{n}+i y_{n}$. A domain of bounded width located on the edge on the half plane is heated by a heat flux with intensity $q$. The other parts of the edge of half plane are thermally insulated. We also assume that the edge of the half plane is free from external loads and that temperature and stresses vanish at infinity. The problem is studied under the conditions of a stationary temperature field.

Consider the problem of heat conduction with the following conditions of thermal contact. We will assume that along the inclusion contour $L_{1}$ the conditions for an ideal thermal contact (temperatures and heat fluxes are equal) are given:

$$
\lambda \frac{\partial T^{+}}{\partial n}=\lambda_{1} \frac{\partial T^{-}}{\partial n}, \quad T^{+}=T^{-}, \quad t_{1}=z_{1} \in L_{1}
$$

and the crack lips $L_{1}$ are thermally insulated

$$
\frac{\partial T^{ \pm}}{\partial n}=0, \quad t_{2}=z_{2} \in L_{2}
$$

Here $n$ is the outer normal to the closed contour $L_{1}$ or to the left face of the cut $L_{2}, \lambda\left(\lambda_{1}\right)$ is the coefficient of thermal conductivity of the matrix (inclusion); $T(x, y)$ stands for the temperature; $t_{k}$ are the complex coordinates of points on the contours $L_{k}$ in local coordinate systems; the plus and minus indices indicate the boundary values of the corresponding values on the left and on the right of the approach to the contour $L_{n}, n=1,2$.

In the problem of thermoelasticity we assume that the conditions of perfect mechanical contact are satisfied along of the inclusion contour $L_{1}$

$$
\begin{aligned}
{\left[N\left(t_{1}\right)+i S\left(t_{1}\right)\right]^{+} } & =\left[N\left(t_{1}\right)+i S\left(t_{1}\right)\right]^{-} ; \\
{\left[u\left(t_{1}\right)+i v\left(t_{1}\right)\right]^{+} } & =\left[u\left(t_{1}\right)+i v\left(t_{1}\right)\right]^{-}, \quad t_{1} \in L_{1} .
\end{aligned}
$$

Suppose that the half plane is subjected to the action of a stationary temperature field $T(x, y)$. Assume that the crack lips $L_{1}$ are not in contact and are free of the loads in the process of deformation

$$
\left[N\left(t_{2}\right)+i S\left(t_{2}\right)\right]^{ \pm}=0, \quad t_{2} \in L_{2} .
$$

In the relations (3), (4), $N_{1}\left(t_{n}\right)$ and $S\left(t_{n}\right), n=1,2$ are the normal and the tangential components of the load and $u\left(t_{1}\right), v\left(t_{1}\right)$ are the components of displacement.

\section{Problem solution}

\subsection{System of integral equations of the problem of heat conduction}

We represent the total temperature in the half plane with an inclusion and crack in the form

$$
T(x, y)=T_{0}(x, y)+T^{*}(x, y)
$$

Mathematical Modeling and Computing, Vol. 7, No. 1, pp. 88-95 (2020) 
where $T_{0}(x, y)$ is the temperature in the homogeneous half plane without an inclusion and a crack caused by the heat flux $q$ and $T^{*}(x, y)$ is the perturbed temperature generated by an inclusion and a crack. The temperature field $T_{0}(x, y)$ is described by the formula [5]

$$
T_{0}(x, y)=-\frac{1}{\pi \lambda} \int_{-c}^{c} q \ln \sqrt{(x-\zeta)^{2}+y^{2}} d \zeta+C, \quad|x|<\infty, \quad|y|<0,
$$

where $C$ is an arbitrary constant.

We represent the temperature $T^{*}(x, y)$ in the form of $T_{*}(x, y)=\operatorname{Re} f(z)$, and we use the complex temperature potential $F(z)=f^{\prime}(z)[8]$

$$
F(z)=\frac{1}{\pi} \int_{L_{1}}\left[\frac{1}{\zeta_{1}-z}-\frac{1}{\zeta_{1}-z}\right] \mu\left(t_{1}\right) d s+\frac{1}{\pi i} \int_{L_{2}}\left[\frac{1}{\xi_{2}-z}-\frac{1}{\bar{\zeta}_{2}-z}\right] \gamma^{\prime}\left(t_{2}\right) d t_{2},
$$

where $\zeta_{k}=t_{k}+z_{k}^{0}(k=1,2), \mu\left(t_{1}\right)$ is an unknown real function on the contour of inclusion $L_{1}, \gamma^{\prime}\left(t_{2}\right)$ is the derivative of the unknown jump of temperature in passing through the crack contour $L_{2}, \bar{\zeta}_{2}$ is the quantity complex conjugate to $\zeta_{2}, d s$ is an element of arc of the contour $L_{1}, f(z)$ is analytic function of the complex variable $\mu_{k}\left(t_{k}\right), k=\overline{1, N}$.

By satisfying the boundary conditions (1) and (2) with the help of the complex temperature potential (6), we obtain the system of two singular integral equations of the first and the second kind for the two unknown functions $\mu\left(t_{1}\right)$ on the contour of an inclusion and $\gamma^{\prime}\left(t_{2}\right)$ on the contour of a crack

$$
\begin{aligned}
& \mu\left(\tau_{1}\right)+\frac{1}{\pi} \int_{L_{1}} \operatorname{Im}\left[K_{11}\left(t_{1}, \tau_{1}\right)+L_{11}\left(t_{1}, \tau_{1}\right)\right] \mu\left(t_{1}\right) d s \\
& \quad+\frac{1}{\pi} \int_{L_{2}} \operatorname{Im}\left[K_{12}\left(t_{2}, \tau_{1}\right)-L_{12}\left(t_{2}, \tau_{1}\right)\right] \gamma^{\prime}\left(t_{2}\right) d t_{2}=-\Delta_{1} \operatorname{Im}\left[F_{0}\left(\eta_{1}\right) e^{i\left(\beta_{1}\right)}\right], \quad \tau_{1} \in L_{1}, \quad(7) \\
& \frac{1}{\pi} \int_{L_{1}} \operatorname{Im}\left[K_{21}\left(t_{1}, \tau_{2}\right)+L_{21}\left(t_{1}, \tau_{2}\right)\right] \mu\left(t_{1}\right) d s \\
& \quad+\frac{1}{\pi} \int_{L_{2}} \operatorname{Im}\left[K_{22}\left(t_{2}, \tau_{2}\right)-L_{22}\left(t_{2}, \tau_{2}\right)\right] \gamma^{\prime}\left(t_{2}\right) d t_{2}=-\operatorname{Im}\left[F_{0}\left(\eta_{2}\right)\right], \quad \tau_{2} \in L_{2} .
\end{aligned}
$$

Here

$$
\begin{gathered}
K_{n k}\left(t_{k}, \tau_{n}\right)=\frac{\Delta_{n} e^{i \beta_{n}}}{i\left(\zeta_{k}-\eta_{n}\right)}, \quad L_{n k}\left(t_{k}, \tau_{n}\right)=\frac{\Delta_{n} e^{i \beta_{n}}}{i\left(\bar{\zeta}_{k}-\eta_{n}\right)}, \quad(k=1,2 ; n=1,2), \\
\eta_{n}=\tau_{n}+z_{n}^{0}, \quad e^{i \beta_{n}}=d \tau_{n} / d s, \quad \Delta_{1}=\frac{\lambda_{1}-\lambda}{\lambda_{1}+\lambda}, \quad \Delta_{2}=1, \\
F_{0}(z)=\frac{\partial T_{0}(x, y)}{\partial x}-\frac{i \partial T_{0}(x, y)}{\partial y},
\end{gathered}
$$

where the temperature $T_{0}(x, y)$ is given by the relation (5).

The solution of the system of integral equations (7) must satisfy the condition

$$
\int_{L_{2}} \gamma^{\prime}\left(t_{2}\right) d t_{2}=0
$$

which provide continuity of temperature by passing the contours of a crack. Under condition (8), the system of integral equations (7) for an arbitrary right-hand side has a unique solution.

Note that the choice of the complex potential in the form (6) ensures the identical satisfaction of the second equality in the condition (1) on the basis of such a choice of analytic continuation from the matrix region in the inclusion region, in which the equality of temperatures for the approach on the left and on the right to the contour of inclusion. 


\subsection{System of integral equations of the problem of thermoelasticity}

By satisfying the boundary conditions (3), (4) with the help of the complex potentials [8], we obtain in the problem of thermoelasticity the system of two singular integral equations of the first and the second kind for the two unknown functions $Q_{1}\left(t_{1}\right)$ on the contour of an inclusion and $Q_{2}\left(t_{2}\right)$ on the contour of a crack

$$
\begin{aligned}
A_{1} Q_{1}\left(\tau_{1}\right)+\frac{1}{2 \pi} \int_{L_{1}} & {\left[R_{11}\left(t_{1}, \tau_{1}\right) Q_{1}\left(t_{1}\right) d t_{1}+S_{11}\left(t_{1}, \tau_{1}\right) \overline{Q_{1}\left(t_{1}\right)} \overline{d t_{1}}\right] } \\
+ & \frac{1}{2 \pi} \int_{L_{2}}\left[R_{12}\left(t_{2}, \tau_{1}\right) Q_{2}\left(t_{2}\right) d t_{2}+S_{12}\left(t_{2}, \tau_{1}\right) \overline{Q_{2}\left(t_{2}\right)} \overline{d t_{2}}\right]=P_{1}\left(\tau_{1}\right), \quad \tau_{1} \in L_{1}, \quad \\
\frac{1}{2 \pi} \int_{L_{1}}\left[R_{21}\left(t_{1}, \tau_{2}\right)\right. & \left.Q_{1}\left(t_{1}\right) d t_{1}+S_{21}\left(t_{1}, \tau_{2}\right) \overline{Q_{1}\left(t_{1}\right)} \overline{d t_{1}}\right] \\
+ & \frac{1}{2 \pi} \int_{L_{2}}\left[R_{22}\left(t_{2}, \tau_{2}\right) Q_{2}\left(t_{2}\right) d t_{2}+S_{22}\left(t_{2}, \tau_{2}\right) \overline{Q_{2}\left(t_{2}\right)} \overline{d t_{2}}\right]=P_{2}\left(\tau_{2}\right), \quad \tau_{2} \in L_{2},
\end{aligned}
$$

where

$$
\begin{gathered}
R_{n k}\left(t_{k}, \tau_{n}\right)=R_{n k}^{1}\left(t_{k}, \tau_{n}\right) \\
-e^{i \alpha_{k}}\left\{\frac{B_{n}}{\bar{T}_{n k}}+\frac{C_{n}\left(\bar{\xi}_{k}-\xi_{k}\right)}{T_{n k}^{2}}+\frac{\overline{d \tau_{n}}}{d \tau_{n}} C_{n} e^{-2 i \alpha_{n}}\left[\frac{\left(2 \eta_{n}-\xi_{k}-\bar{\eta}_{n}\right)\left(\bar{\xi}_{k}-\xi_{k}\right)}{T_{n k}^{3}}\right]-\frac{1}{T_{n k}}\right\}, \\
S_{n k}\left(t_{k}, \tau_{n}\right)=S_{n k}^{1}\left(t_{k}, \tau_{n}\right)+e^{-i \alpha_{k}}\left[\frac{B_{n}\left(\xi_{k}-\bar{\xi}_{k}\right)}{\bar{T}_{n k}^{2}}+\frac{C_{n}}{T_{n k}}-\frac{\overline{d \tau_{n}}}{d \tau_{n}} C_{n} e^{-2 i \alpha_{n}} \frac{H_{k n}}{\bar{T}_{n k}^{2}}\right], \overline{\tau_{n}} \\
R_{n k}^{1}\left(t_{k}, \tau_{n}\right)=e^{i \alpha_{k}}\left[\frac{B_{n}}{H_{k n}}-\frac{\overline{d \tau_{n}}}{d \tau_{n}} \frac{C_{n} e^{-2 i \alpha_{n}}}{\bar{H}_{k n}}\right] S_{n k}^{1}\left(t_{k}, \tau_{n}\right)=-C_{n} e^{-i \alpha_{k}}\left[\frac{1}{\bar{H}_{k n}}-\frac{e^{-2 i \alpha_{n}} H_{k n}}{d \tau_{n}} \frac{\bar{H}_{k n}^{2}}{k n}\right] \\
H_{k n}=\xi_{k}-\eta_{n}, \quad T_{n k}=\xi_{k}-\overline{\eta_{n}}, \quad(k=1,2 ; n=1,2) \\
A_{1}=0.5\left[1+\chi_{1}+\Gamma_{1}(1+\chi)\right], \quad B_{1}=\chi_{1}-\Gamma_{1} \chi, \quad C_{1}=1-\Gamma_{1}, \quad B_{2}=1, \quad C_{2}=-1, \\
P_{1}\left(\tau_{1}\right)=\Gamma_{1} \beta_{t} f^{-}\left(\eta_{1}\right)-\beta_{t}^{1} f^{+}\left(\eta_{1}\right), \quad P_{2}\left(\tau_{2}\right)=0, \\
\chi=3-4 \mu, \quad \beta^{t}=\alpha^{t} E, \quad \chi_{1}=3-4 \mu_{1}, \quad \beta_{1}^{t}=\alpha_{1}^{t} E_{1}, \quad \Gamma_{1}=G_{1} / G . \\
Q_{1}\left(t_{1}\right)=g_{1}\left(t_{1}\right), \quad t_{1} \in L_{1} \\
Q_{2}\left(t_{2}\right)=g_{2}^{\prime}\left(t_{2}\right)+\frac{i \beta^{t}}{1+\chi}\left[f^{+}\left(t_{2}\right)-f^{-}\left(t_{2}\right)\right], \quad t_{2} \in L_{2} .
\end{gathered}
$$

The functions $f^{ \pm}\left(\eta_{1}\right)$ are defined as the limiting values of potential $f(z)$. The unknown function $g_{2}^{\prime}\left(t_{2}\right)$, which is the derivative of the jump of displacements in passing through the crack contour, is sought in the class of Hölder function with integrable singularities at the crack tips.

Here are the following designations: $\chi=(3-\mu) /(1+\mu), \beta^{t}=\alpha^{t} E(1+\mu)$ are for a plane stressed state; $\alpha^{t}, G, E\left(\alpha_{1}^{t}, G_{1}, E_{1}\right)$ are the coefficient of linear thermal expansion, shear modulus, Young's modulus, $\mu\left(\mu_{n}\right)$ is Poisson's ratio material of the matrix (the inclusion), respectively.

The system of integral equations (9) has a unique solution for an arbitrary right-hand side under the condition

$$
\int_{L_{2}} g_{2}^{\prime}\left(t_{2}\right) d t_{2}=0
$$

By using the relation (10), we represent the condition in the form

$$
\int_{L_{2}} Q_{2}\left(t_{2}\right) d t_{2}=-\frac{2 i \beta^{t}}{1+\chi} \int_{L_{2}} t_{2} \gamma^{\prime}\left(t_{2}\right) d t_{2}
$$

Condition (12) ensures the uniqueness of the displacements by passing the contours of cracks. 
We note that the choice of complex potentials in the form [8] ensures the identical satisfaction of the first equality in the condition (3) on the contours of inclusions on the basis of such a choice of an analytic continuation from the matrix region in the inclusion region, in which the stresses are continuous for the approach to the contours of inclusions on the left and on the right.

The algorithm used for the solution of the analyzed problem can be described as follows: the system of integral equations (7), (8) of the problem of heat conduction is used to find the functions $\mu\left(t_{1}\right)$ and $\gamma^{\prime}\left(t_{2}\right)$. Substituting these functions in the system of equations (9), (12) of the problem of thermoelasticity allows us to find the unknown functions $Q_{1}\left(t_{1}\right)$ and $Q_{2}\left(t_{2}\right)$. Then the stress intensity factors (SIF) $K_{I}$ and $K_{I I}$, which are the real quantities that characterize the stress-deformed state in the vicinity of the crack tips, are found according to the formula [14]

$$
K_{I}^{ \pm}-i K_{I I}^{ \pm}=\mp \lim _{t_{2} \rightarrow l_{2}^{ \pm}}\left[\sqrt{2 \pi\left|t_{2}-l_{2}^{ \pm}\right|} Q_{2}\left(t_{2}\right)\right]
$$

where the lower signs correspond to the left of crack tip $\left(l_{2}^{-}\right)$, and the upper ones correspond to the right crack tip $\left(l_{2}^{+}\right)$. The numerical solution of the system of equations (7), (8), and (9), (12) is found by the method of mechanical quadratures [14].

\section{Numerical analysis}

We consider an elastic half plane containing an elastic circular inclusion of radius $R$ and internal rectilinear thermally insulated crack of length $2 l$. The crack is parallel to the edge of the half plane and its center is located in the $O x$-axis. The centers of the inclusion and the crack are located on the distance $h$ to the edge of half plane and the distance between them is equal to $d$. Assume that half plane is heated in a region of width $2 c$ of the free edge due to a uniformly distributed heat flux of constant intensity $q=$ const. The center of thermal action is located in the origin of the coordinate system $x O y$ (see Fig. 1).

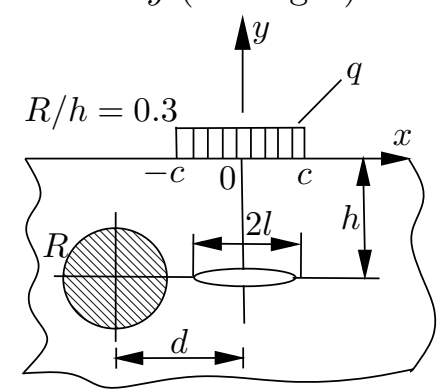

Fig. 1. Schematic diagram of heating of a half plane containing an inclusion and a crack.
The plots of the dependencies of the dimensionless stress intensity factors (SIFs)

$$
k_{1}^{ \pm}=K_{\mathrm{I}}^{ \pm} \lambda(1+\chi) / q \beta_{\mathrm{t}} l \sqrt{l}, \quad k_{2}^{ \pm}=K_{\mathrm{II}}^{ \pm} \lambda(1+\chi) / q \beta_{\mathrm{t}} l \sqrt{l}
$$

on the distance between the center of the inclusion and the crack $d^{*}=d / h$ for values of dimensionless parameters $c / h=0.25$, $l / h=0.5, R / h=0.3$ are depicted in Fig. 2. The solid lines correspond to the left tip of the crack $\left(k_{1}^{-}, k_{2}^{-}\right)$, whereas the dashed lines correspond to its right tip $\left(k_{1}^{+}, k_{2}^{+}\right)$.

The numerical analysis was carried out for two types of matrixinclusion composites (aluminum- steel and steel-aluminum). We used the following values of the parameters: $\left(E=192 \mathrm{GPa}, \alpha^{t}=17.0 \cdot 10^{-6} \mathrm{~K}^{-1}, \lambda=16.7 \mathrm{~W} /(\mathrm{m} \cdot \mathrm{K})\right.$, $\mu=0.283)$ for steel and $\left(\alpha^{t}=23.8 \cdot 10^{-6} \mathrm{~K}^{-1}, E=68 \mathrm{GPa}, \lambda=209 \mathrm{~W} /(\mathrm{m} \cdot \mathrm{K}), \mu=0.34\right)$ for aluminum [16].

For the aluminum-steel (matrix-inclusion) composition SIFs $k_{1}^{ \pm}$at both crack tips decrease as the inclusion approaches the crack (Fig. 2a). For the SIFs $k_{2}^{ \pm}$we observe different picture: if the inclusion approaches the crack, then the SIF $k_{2}^{-}$for the crack tip located closer to the inclusion decreases and the quantity $\left|k_{2}^{+}\right|$increases (Fig. 2b). For the steel-aluminum (matrix-inclusion) composition SIFs $k_{1}^{ \pm}$ at both crack tips also decrease as the inclusion approaches the crack (Fig. 2c). At the same time, the SIF $k_{2}^{-}$(for the crack tip located closer to the inclusion) increases and the quantity $\left|k_{2}^{+}\right|$decreases. Moreover, if the distance between the centers of the inclusion and crack is $d^{*}=5$, then the influence of the inclusion is quite weak and the values of the SIFs $k_{1}^{ \pm}$and $k_{2}^{ \pm}$are practically equal to their values obtained for the homogeneous half plane containing a crack [5]. 
In the considered problem, the lips of the crack are not in contact. Then, according to the $\sigma_{\theta}$-criterion (based on the hypothesis of the initial growth of the crack) from equations of the boundary equilibrium [17] it is possible to find the critical values of the heat flux $q_{c r}$ at which the growth of the crack and the local destruction of the body begin according to the formula

$$
\begin{gathered}
q_{c r}=K_{q} \frac{K_{1 C}}{\cos ^{3} \frac{\theta_{*}}{2}\left(k_{1}^{ \pm}-3 k_{2}^{ \pm} \tan \frac{\theta_{*}}{2}\right)}, \\
K_{q}=\frac{(1+\chi) \lambda}{\alpha^{t} E l \sqrt{\pi l}}
\end{gathered}
$$

where $K_{1 C}$ is a constant of material that characterizes the resistance of the material to the destruction and is determined experimentally; $\theta_{*}=$ $2 \arctan \frac{k_{1}^{ \pm}-\sqrt{\left(k_{1}^{ \pm}\right)^{2}+8\left(k_{2}^{ \pm}\right)^{2}}}{4 k_{2}^{ \pm}}$is an angle of initial growth of the crack.

In the partial case for the aluminum-
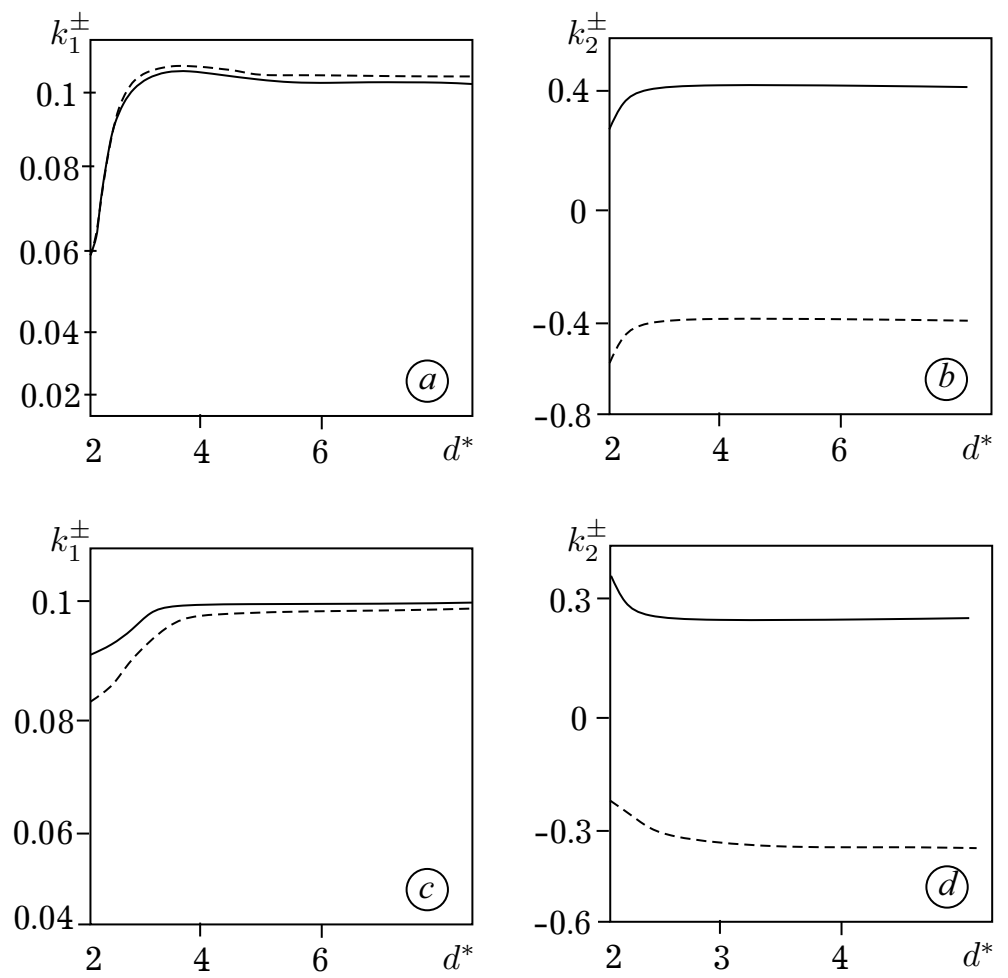

Fig. 2. Dependencies of dimensionless SIFs $k_{1}^{ \pm}$and $k_{2}^{ \pm}$on the distance between the centers of the inclusion and the crack $d^{*}=$ $d / h$ for the two types of matrix-inclusion composites: aluminumsteel $(a, b)$ and steel-aluminum $(c, d)$.

steel (matrix-inclusion) composition we obtain: if $d^{*}=2$, then $q_{c r}=2.01 K_{q} K_{1 c}$, if $d^{*}=5$, then $q_{c r}=1.61 K_{q} K_{1 c}$; for the steel-aluminum (matrix-inclusion) composition we obtain: if $d^{*}=2$, then $q_{c r}=2.19 K_{q} K_{1 c}$, if $d^{*}=5$, then $q_{c r}=2.30 K_{q} K_{1 c}$.

\section{Conclusions}

1. The two-dimensional mathematical models of the problems of stationary heat conductivity and thermoelasticity for an elastic half plane with an inclusion and a crack in the form of a system of singular integral equations (SIEs) of the ?rst kind for the contour of the crack and a system of the second kind for the contour of the inclusion are constructed. This approach allows us to obtain a numerical solution of the system of SIEs by applying the method of mechanical quadratures.

2. Numerical solution of the system of SIEs in the particular case of a half plane with a circular inclusion and rectilinear thermally insulated crack due to a heat flux of constant intensity is obtained. On the basis of this solution, stress intensity factors (SIFs) at the crack tips are calculated, which in the future will be used to determine the critical values of the heat flux at which the crack begins to grow.

3. Based on the analysis of the obtained critical values $q_{c r}$ of the heat flux, it follows: if the more rigid inclusion (steel-inclusion) approaches the crack, then the critical value of the heat flux $q_{c r}$ increases (at which the growth of the crack in the left tip begins); if the less rigid inclusion (aluminum-inclusion) approaches the crack, then, on the contrary, it causes the decreasing of $q_{c r}$. A similar situation is observed for the right tip of the crack.

[1] Sekine H. Thermal stress singularities at tips of a crack in a semi-infinite medium under uniform heat flow. Engineering Fracture Mechanics. 7 (4), 713-729 (1975).

[2] Sekine H. Thermal stresses near tips of an insulated line crack in a semi-infinite medium under uniform heat flow. Engineering Fracture Mechanics. 9 (2), 499-507 (1977). 
[3] Tweed I., Lowe S. The thermoelastic problem for a half-plane with an internal line crack. International Journal of Engineering Science. 17 (4), 357-363 (1979).

[4] Konechnyj S., Evtushenko A., Zelenyak V. The effect of the shape of distribution of the friction heat flow on the stress-strain state of a semispace. Trenie i Iznos. 23, 115-119 (2002).

[5] Matysiak S. J., Evtushenko A. A., Zelenyak V. M. Frictional heating of a half-space with cracks. I. Single or periodic system of subsurface cracks. Tribology International. 32 (5), 237-242 (1999).

[6] Zelenyak V. M., Kolyasa L. I. Thermoelastic state of a half plane with curvilinear crack under the conditions of local heating. Materials Science. 52, 315-322 (2016).

[7] Konechny S., Evtushenko A., Zelenyak V. Heating of the semispace with edge cracks by friction. Trenie i Iznos. 22, 39-45 (2001).

[8] Matysiak S., Evtushenko A., Zelenyak V. Heating of a half space containing an inclusion and a crack. Materials Science. 40, 467-474 (2004).

[9] Hasebe N., Wang X., Saito T., Sheng W. Interaction between a rigid inclusion and a line crack under uniform heat flux. International Journal of Solids and Structures. 44 (7-8), 2426-2441 (2007).

[10] Kit G. S., Krivtsun M. G. Plane thermoelasticity problems for bodies with cracks. Kiev, Naukova dumka (1983), (in Russian).

[11] KitH.S., Chernyak M.S. Stressed state of bodies with thermal cylindrical inclusions and cracks (plane deformation). Materials Science. 46, 315-324 (2010).

[12] Chen H., Wang Q., Liu G., Sun J. Simulation of thermoelastic crack problems using singular edge-based smoothed finite element method. International Journal of Mechanical Sciences. 115-116, 123-134 (2016).

[13] Choi H. J. Thermoelastic interaction of two offset interfacial cracks in bonded dissimilar half-planes with a functionally graded interlayer. Acta Mechanica. 225, 2111-2131 (2014).

[14] Savruk M. P. Two-dimensional elasticity problem for bodies with cracks. Kiev, Naukova dumka (1981), (in Russian).

[15] Erdogan F., Gupta G. D., Cook T. S. Numerical solution of singular integral equations. In: Sih G. C. (eds) Methods of analysis and solutions of crack problems. Mechanics of fracture, vol. 1. Springer, Dordrecht. 368-425 (1973).

[16] Podstrigach Ya. S., Burak Ya. Y., Hachkevych O. R., Chernyavskaya L. V. Thermoelasticity of electrically conductive bodies. Kiev, Naukova Dumka (1977), (in Russian).

[17] Panasyuk V. V., Savruk M. P., Datsyshin A. P. Stress distribution around cracks in plates and shells. Kiev, Naukova Dumka (1976), (in Russian). 


\title{
Математичне моделювання стаціонарного термопружного стану в півплощині з включенням і тріщиною за дії локального нагрівання тепловим потоком
}

\author{
Зеленяк В. М. \\ Національний університет "Львівсъка політехніка", \\ вул. С. Бандери, 12, Львів, 79013, Україна
}

Розглянуто двовимірні стаціонарні задачі теплопровідності та термопружності для напівнескінченного пружного тіла, що містить включення та тріщину. Для цього побудовано математичні моделі цих двовимірних задач у вигляді системи сингулярних інтегральних рівнянь (CIP) першого та другого роду. Числовий розв'язок системи інтегральних рівнянь одержано методом механічних квадратур у разі пружної півплощини, що локально нагрівається тепловим потоком і містить кругове виключення та теплоізольовану прямолінійну тріщину. Отримано графічні залежності коефіцієнтів інтенсивності напружень (KIH), які характеризують розподіл інтенсивності напруженнь у вершинах тріщини, залежно від пружних та термопружних характеристик включення та матриці, від відносного положення тріщини та включення. Отримані результати використані для визначення критичних значень теплового потоку, за якого тріщина починає рости. Ця модель є розвитком відомих моделей двовимірних стаціонарних задач теплопровідності та термопружності для кусково-однорідних тіл 3 тріщинами.

Ключові слова: термопружність, коефічієнт інтенсивності напружень, сингулярне інтегральне рівняння, включення, теплопровідність, тріщина, тепловий поmik. 